\title{
Reenactment: An embodied cognition approach to meaning and linguistic content
}

\author{
Sergeiy Sandler \\ Department of English Language and Literature, University of Haifa \\ sergeiys@gmail.com
}

This is a draft version of the paper. The final paper is forthcoming in Phenomenology and the Cognitive Sciences.

\begin{abstract}
A central finding in experimental research identified with Embodied Cognition (EC) is that understanding actions involves their embodied simulation, i.e. executing some processes involved in performing these actions. Extending these findings, I argue that reenactment - the overt embodied simulation of actions and practices, including especially communicative actions and practices, within utterances - makes it possible to forge an integrated EC-based account of linguistic meaning. In particular, I argue: (a) that remote entities can be referred to by reenacting actions performed with them; (b) that the use of grammatical constructions can be conceived of as the reenactment of linguistic action routines; (c) that complex enunciational structures (reported speech, irony, etc.) involve a separate level of reenactment, on which characters are presented as interacting with one another within the utterance; (d) that the segmentation of long utterances into shorter units involves the reenactment of brief audience interventions between units; and (e) that the overall meaning of an utterance can be stated in reenactment terms. The notion of reenactment provides a conceptual framework for accounting for aspects of language that are usually thought to be outside the reach of EC in an EC framework, thus supporting a view of meaning and linguistic content as thoroughly grounded in action and interaction.
\end{abstract}

Keywords: action; cognitive linguistics; dialogue; embodied cognition; meaning; simulation. 
Language has often been viewed as the epitome of abstract cognition, as formal logical calculus in thin disguise. Accordingly, in the debates around embodied cognition (EC) and embodied social cognition, ${ }^{1}$ raging in cognitive science today, the supposedly disembodied nature of language and meaning - abstract concepts, logical syntactic rules, etc. - counts against EC.

EC-based and related approaches instead tend to view language as a tool of human action and interaction (e.g. Tylén et al. 2010). However, these approaches face a challenge when dealing with linguistic content: if we view utterances consistently as actions, how do we account for the meanings of their parts (e.g. words, phrases) and for the relation between the meanings of these parts and the meaning of a whole utterance in action terms? This challenge is addressed from several perspectives in recent literature (e.g. Borghi and Cimatti 2009; Croft 2001; Gasparov 2010; Goldberg 2006; Pascual 2002), but many parts of the puzzle are still missing. Moreover, the connection between this linguistic literature and the more general principles of action understanding proposed in EC theories (e.g. Gallese 2003) is not always made clear.

In this paper I propose the notion of reenactment as a conceptual framework for extending the semantics of actions to include the semantics of utterances and their parts. By reenactment I mean the overt embodied simulation of action, including communicative action, within utterances, as part of their content. As I will show, this notion offers a clear conceptual link between the theory that understanding actions involves embodied simulation, central to some of the EC literature, and research in cognitive linguistics - particularly Construction Grammar (Croft 2001; Goldberg 2006) and work on intersubjectivity in language (e.g. Brandt and Brandt 2005; Du Bois forthcoming; Pascual 2002; Verhagen 2005; Zlatev et al. 2008). ${ }^{2}$ Furthermore, the proposed framework can be extended to phenomena that received little attention in EC and cognitive linguistic literature. I will particularly focus on reference to remote objects and complex enunciational structures, such as reported speech and irony.

These linguistic theories and phenomena are discussed in the latter part of the paper. Before that, a more detailed discussion is due of the notion of reenactment itself, its connection to EC, and the conception of meaning it presumes.

\footnotetext{
${ }^{1}$ I will address social cognition only in the basic sense of meaningfully interacting with others, ignoring issues that have to do with the so-called "theory of mind".

${ }^{2}$ I am thus following a programme akin to that of Gallese and Lakoff (2005). However, Gallese and Lakoff focus on the semantics of concepts, while my focus here will be on the semantics and construction of utterances.
} 


\section{Reenactment and embodied cognition}

\section{An action-centered notion of meaning}

EC is a label that means different things to different people (see Wilson 2002 for an overview). One may distinguish between different understandings of EC according to the sense in which cognition is said to be embodied. On one view, "embodied" should be understood literally, as referring to the body. Thus, Goldman and de Vignemont (2009) define EC as assigning a central role in cognition to the body (minus the brain) of the cognizer. Another view (e.g. Borghi and Cimatti 2010) understands embodiment as the claim that there is an intimate and necessary link between cognition and action. ${ }^{3}$ It is this latter view of EC that I will adopt.

Now, we have a clear sense of how actions can bear meaning: I understand what an action means when I realize what the person performing it is trying to accomplish by it and how it may affect me, as one who might respond to it. As agents living in an environment occupied by other agents and as social beings, actions are intrinsically meaningful to us. But action meaning does not behave in the same way as the received view tells us word and sentence meanings behave. We do not expect two actions of the same type to mean the same thing in different situations: Pressing on a pedal means one thing when playing a piano and another when driving a car. We also do not expect action-meanings to be fixed. Thus, by moving my fingers I am typing, editing a document, writing a paper, expressing my opinion, trying to promote my academic career, avoiding other commitments, spending the laptop battery, and so on (cf. Rommetveit 1992). Each of these descriptions can count as what my current action means to me or to others, and it may well mean different things to different people at different times. Action meanings are expected to evolve and be negotiated in interaction. There is no entity that is the meaning of an action.

There is a long-standing tradition aiming to account for linguistic meaning in terms of action-meaning. This is the mainstream approach in pragmatics (following Austin 1962). However, the traditional division of labor between pragmatics and semantics has left it to pragmatics to account for the meaning of utterances as actions, based on a referential-logical interpretation of their content. EC challenged this division of labor by proposing an account of concept meaning in terms of action meaning. Gallese and Lakoff (2005) argue, on neurological

\footnotetext{
${ }^{3}$ Merleau-Ponty (1962) is usually cited as the chief philosophical inspiration behind EC (following Noë 2004). Merleau-Ponty indeed emphasized the place of the body in his phenomenology, but in his view too, the body is
} 
and linguistic grounds, that our grasp of concepts that involve bodily actions, and possibly of their metaphorical extensions (Lakoff and Johnson 1980), involves simulating these actions, i.e. partly performing them in the motor system of the brain. ${ }^{4}$

Borghi and Cimatti (2009) propose an important extension of this approach to account for abstract words. They raise the hypothesis that linguistic meaning is grounded in our embodied social experience. That is, we experience the use of words, our own and others', in various social settings as a situated bodily action, physically performed by moving one's lips or fingers, etc., that uses these words as tools. We may have no direct experience of the objects represented by abstract words, such as "freedom" or "God", but we have ample experience of occasions on which these words have been used, just as we have experience of grasping objects or of hammering a nail, and it is this experience that forms the basis for our understanding of them. Words are social actions and thus have embodied action-meanings. Word meanings are therefore grasped through simulating the communicative behavior of oneself and others.

This extension of EC, while it requires further empirical support, is a crucial step toward the goal of creating a consistently embodied approach to language, one that conceives of linguistic meaning as embodied action-meaning on all levels. However, in one important sense it is insufficient: It is restricted to word meanings. There is still a gap in explaining the link between the action-meanings of words and the meanings of whole utterances.

It is here that the notion of reenactment may be of use. As I will show below, reenactment offers a conceptual framework that bridges work on the semantics of simple bodily actions with work in cognitive linguistics that studies the construction of utterances (e.g. Croft 2001 and Goldberg 2006), and in turn also with the pragmatic understanding of utterance meaning.

the acting, situated human body, rather than the anatomy per se.

${ }^{4}$ The term "simulation", central to my argument, can be used in different ways. A specific usage has developed in the EC literature (and I shall adhere to it in this paper), which takes the word "simulation" to imply embodied simulation. Such simulation involves the (partial) imitation of the simulated action, rather than manipulation of abstract representations. At least in the case of simple bodily actions (on which current research focuses), simulation is performed in the motor system of the brain, rather than in a part of the brain dedicated to abstract reasoning or logical calculus (Gallese and Lakoff 2005). Since I understand embodiment to be related to action, rather than to the body per se, I take embodied simulation to involve some aspect of performing an action, even if it is not a bodily action. 


\section{What is reenactment?}

A growing body of empirical research (e.g. Aziz-Zadeh and Damasio 2008; Fischer and Zwaan 2008; Gallese 2003; 2008; Gallese and Lakoff 2005; Grafton 2009; Jirak et al. 2010; Pulvermüller 2005 ) indicates that the understanding of actions involves embodied simulation. Famously, the Mirror Neuron System is involved both in observing (or hearing) an action performed and in performing the same action, in monkeys and in humans (Grafton et al. 1996; Iacoboni et al. 1999; Rizzolatti and Craighero 2004; Rizzolatti et al. 1996). This remains true when the action is partly concealed: seeing an arm reaching for an object hidden behind a curtain causes neurons involved in the motor action of grasping to fire, presumably since grasping is understood as the purpose of the action (Umiltà et al. 2001).

In the context of these findings, reenactment can be defined as overt simulation. It happens whenever a person does something for communicative purposes, which is meant to be recognizable as a particular action (including communicative actions). In other words, a reenacted action is performed by the speaker as part of her utterance, so as to be simulated by her audience.

A simple example of reenactment can be observed in Transcript $1:^{5}$

Transcript 1 (SBC048: 32.939-39.263)

LEA: $\quad($ GASP $)=$

TIM: $\begin{aligned} \quad .0 h= & {[\mathrm{my}=] } \\ & {[@ @] }\end{aligned}$

LEA: Look at that.

JUDY: (H) [@

TIM: $\quad$ A Mickey [Mouse watch.

LEA: [That's [just what I always@wanted.]

Lea is opening a Christmas gift. Her turns consist of formulaic expressions: "[gasp] oh my gosh" and "look at that" express amazement; "just what I always wanted" expresses appreciation of something one has received. These phrases are regularly used to perform just these actions (in the relevant circumstances) and using them Lea reenacts communicative routines she has seen in action, and probably used, many times in the past. These actions are

\footnotetext{
${ }^{5}$ All transcripts are taken from the Santa Barbara Corpus of Spoken American English (Du Bois and Englebretson 2004; 2005). The transcription conventions are as used in the corpus (Du Bois et al. 1993), with slight simplification. Lines in the transcript correspond to intonation units (Chafe 1993). Other common symbols are: “@” (laughter), “=” (prolonged syllable), “(H)”, and “(Hx)” (audible inhaling and exhaling respectively). Several dots indicate a pause, proportional in length to the number of dots. The heading includes the filename and the location of the cited segment in the audio file.
} 
also recognizable as such to her interlocutors (and can thus be simulated by them). Indeed, that is their point.

As reenacted actions are situated in the context of an utterance, there is a necessary interplay between repetition and innovation involved. To be recognizable as a particular action, the current action sequence has to repeat some salient elements of actions performed in the past. On the other hand, even the most accurate repetition always forms part of a new utterance by the person performing it, with its unique context and co-text, which always leads to the reenacted action sequence being profiled and construed in a novel way. Moreover, facing ever new circumstances and pursuing ever changing communicative goals, speakers may use reenactment with deliberate flexibility, to attain the desired construal by and response from their audience. In this respect I assume that actions follow the same logic as prototypes (Rosch 1973) in general: Non-prototypical instances of an action are recognizable as related to prototypical ones.

One may further distinguish between two levels of reenactment. The first (I will sometimes refer to it as "appropriation") foregrounds the simulated action itself, while the second (I will also call it "polyphony") foregrounds the act of performing it, thus introducing into the utterance a character ("onstage conceptualizer" is an equivalent term used in cognitive linguistics), distinct from the speaker.

The term "polyphony" reflects the origins of the notion of reenactment in Mikhail Bakhtin's (1981; 1984; 1986) dialogic philosophy of language (and cf. Ducrot 1984), specifically in his claim that utterances not only participate in dialogue, but are also dialogic from within. According to Bakhtin, our utterances are made of other people's utterances. Reenactment is essentially a restatement of this principle in up-to-date terms.

The example in Transcript 1 is clearly a case of appropriation. Lea took phrases used by previous speakers to perform particular actions, and applied them to the unique context of her own utterance. Transcript 2 offers an example of polyphony:

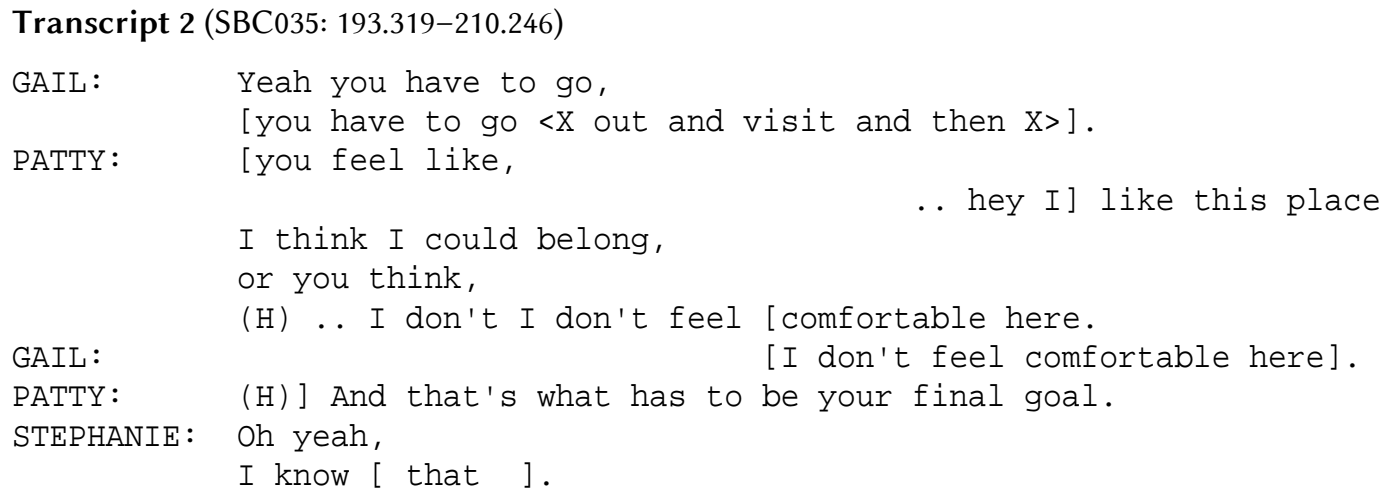


PATTY :

[A place] that has what you want,

STEPHANIE :

PATTY:

but you feel good a[bout it].

[ But ],

You walk on campus and you think,

hey there's something about this [place,

MAUREEN :

PATTY:

(H) that,

[ $<X$ I'll X $>$ dump this outside],

.. that] speaks to me,

Gail and Patty put words in Stephanie’s mouth: "Hey, I like this place. I think I could belong”, "I don't... I don't feel comfortable here”, "Hey, there's something about this place that... that speaks to me". ${ }^{6}$ These are all expressions of attitudes, and are meant to be simulated by the audience as such. But neither Patty nor Gail expresses these attitudes herself. Rather, their utterances exhibit the expression of these attitudes by a character (identified with Stephanie). As we shall see below, utterances often feature several such characters acting upon one another. ${ }^{7}$

\section{Reenactment and meaning}

As noted above, my aim in this paper is to offer the notion of reenactment as a building block for an EC-based conceptual framework in which the meaning of linguistic utterances can be considered on all levels. However, I have no general argument to offer to establish such a conceptual framework. Rather, I will consider several different aspects of linguistic meaning

\footnotetext{
${ }^{6}$ While the words are attributed to Stephanie, it does not imply that she actually said, or will say, them. This is a typical case of what Pascual (2002) calls "fictive interaction”. By definition, all cases of fictive interaction are also cases of polyphonic reenactment: They involve characters presented as interacting with one another within an utterance. But polyphony is a broader category, not limited to the fictive. Thus, a faithful quotation would not count as fictive interaction, but would still exhibit polyphony.

${ }^{7}$ It is common in the cognitive linguistics literature dealing with forms of polyphony (e.g. Brandt and Brandt 2005; Pascual 2002; Verhagen 2005) to describe these phenomena in terms of mental spaces (Fauconnier 1994; Fauconnier and Turner 2002): Each character occupies a mental space. Such usage offers a clear link between work on polyphony and intersubjectivity in language and mainstream cognitive linguistics, and is not alien to mental space theory itself (see e.g. Coulson and Fauconnier 1999). However, on the philosophical level the appeal to mental spaces is problematic, especially for an account committed to an EC perspective. After all, mental spaces are abstract entities, and an account of language that reduces actual utterances to abstract entities is hardly in the spirit of EC. Rather, polyphony involves the actual or potential perspectives of agents, real or imagined (including personified inanimate objects and abstract ideas; cf. Cooren 2010). It may or may not be the case that our ability to entertain mental spaces in general somehow stems from our ability to consider how other people act and perceive the world, but I do not believe, and would not want to imply, that the converse is true.
} 
and forms of organizing utterances, and show how they can be described as forms of reenactment.

In particular, I shall discuss reference to remote or concealed entities in discourse, the use of grammatical constructions (as understood in Construction Grammar), some complex enunciational structures, the segmentation of long utterances, and finally the overall pragmatic meaning of utterances. Often my aim will be to show how established theories can be stated in reenactment terms. This is meant as an attempt to point toward a possible integrated account, rather than to replace existing work.

\section{Reenactment and reference}

A central challenge that EC-based accounts of language face has to do with reference to things not present to the speaker and audience. The meaning of abstract words has received the most attention in the literature (see Borghi and Cimatti 2009 and works cited there), but the same issue arises regarding remote objects, past or future events, people's thoughts and emotions, and fictional entities. In all cases the question is the same: People's utterances often talk about things, while actions are not about anything. How can this aboutness of language be accounted for in action terms? To be sure, referring and describing are communicative actions too, with specific expressions and more generic constructions dedicated to performing them (I shall return to this below), but they exploit the already given aboutness of language, not explain it.

But in fact, there is a broad class of cases in which reference to remote entities is achieved by means of reenactment. Consider what happens if, for example, I move my hand in a way that is recognizable as grasping some object (that is, if I reenact grasping it), without the object itself being present at the scene. Given the right setting, my interlocutor will then simulate the action of grasping the missing object, and I will have successfully referred to it.

To move from hypothetical descriptions to linguistic reality, consider how some nouns are formed in sign languages (Padden et al. 2010). Signs designating hand-held objects and appliances are usually iconic rather than arbitrary. These signs, whether or not they also contain some feature that visually resembles the object denoted, reenact the way the object is handled. Thus, the American Sign Language (ASL) sign for "trombone” is holding one's hands as if playing a trombone and moving one of them back and forth; the ASL sign for "towel" is holding up your hands and moving them sideways as if holding a towel and rubbing the back of your neck with it, etc. 
The use of reenactment to talk about remote or otherwise inaccessible objects is not limited to sign languages. Consider Transcript 2 again. While Patty, in her advice to Stephanie, uses the words "feel" and "think", these words do not describe exactly what thoughts and feelings she is talking about. Instead, Patty uses reenactment: She picks out the emotional states she wants to refer to using phrases typically used to express them ("I don't feel comfortable here", "I think I could belong"). This allows her to pinpoint the feelings she is referring to with much greater precision than the seemingly explicit "you feel good about it". Indeed, as de Vries (2010) shows (and cf. Ekić and Pascual 2011), reenactment is the only way to refer to mental and emotional states in some languages.

\section{Constructions as communicative action routines}

Construction Grammar $(\mathrm{CxG})$ is the most important approach to grammar within cognitive linguistics. ${ }^{8} \mathrm{CxG}$ rejects the distinction between lexicon and syntax: Instead of words being meaningful on their own and sentences as combinations thereof, the utterance is seen as a nested array of units. Words, phrases, idioms, and sentences are all constructions, and each construction bears meaning as a whole, over and above the meanings of the smaller constructions that are its parts.

My claim is that $\mathrm{CxG}$ can be interpreted in a way consonant with the conceptual framework of reenactment. Specifically, I propose that constructions ${ }^{9}$ can be thought of as communicative action routines. Recognizing and understanding constructions would then involve the audience simulating these communicative actions, and the use of constructions in discourse would hence trivially be a case of reenactment. While the empirical work needed to establish that constructions are treated by language users as actions is something that I cannot hope to undertake here, I will make a few remarks suggesting that such an interpretation of $\mathrm{CxG}$ is reasonable.

\footnotetext{
${ }^{8}$ There are many different strands within CxG, not all of which fit an EC-based account of language equally well. My focus here is on the more radical and usage-based approaches, such as that of Croft (2001), and to a lesser extent of Goldberg (2006). Also relevant is Gasparov's (2010) theory of grammar, which is de facto a version of $\mathrm{CxG}$ even as he does not identify it as such. All these theories follow the more general principles laid out in Langacker (1987).

${ }^{9}$ The arguments in this section apply to such textbook cases of constructions as formal idioms (Fillmore, Kay and O’Connor 1988) and argument structure constructions (focused on in Goldberg 2006). Applications of CxG involving intersubjectivity are dealt with separately below.
} 
Already Fillmore, Kay and O'Connor (1988) note that some constructions have a pragmatic point as part of their meaning. Thus $\mathrm{CxG}$ does not postulate any syntactic level which is a priori action-free. Moreover, constructions that do not have a pragmatic point in the ordinary sense, can still be viewed as performing such communicative actions as describing, informing, mentioning, or drawing attention to their respective objects, etc. After all, saying is a kind of doing.

The variation and hierarchic structure that exists between constructions seems to parallel the variation and hierarchic structure that exists between actions in general. Constructions vary from fixed to free. Thus, the idiom "by and large" is a fixed construction, which may only be used in this specific form. The ditransitive construction, on the other hand, has no fixed verbal content at all. Such a construction as "The [comparative], the [comparative]" occupies a space in between: it has some fixed parts and some lacunae to be filled in. There are also inheritance and inclusion relations between constructions. For example, "The more the merrier" instantiates the "The [comparative], the [comparative]" construction, but it is also an idiom, and as such is a construction in its own right, which inherits some properties from the more general construction it instantiates. "The sooner you kick the habit, the longer your life expectancy is going to be" is another instantiation of the "The [comparative], the [comparative]" construction, which includes in it other constructions that affect the meaning of the whole, such as "kick the habit".

Action routines exhibit similar variation and structure: Some are relatively specific in their detail (cooking rice for dinner, sipping coffee from an overfilled mug), while others may be instantiated in a wide variety of specific forms (surfing the web, dancing, writing). Some are relatively brief and simple (pressing a button, picking up the phone), while others are long and complex (organizing a conference, traveling abroad). Some are more specific instantiations of more general others (cooking rice for dinner is an instance of making dinner). Some are included as sub-segments in others (pouring water into the pot as part of cooking rice for dinner). All actions are meaningful holistically, through the purpose and repercussions of the action as a whole, but this holistic action-meaning exhibits similar inheritance and inclusion relations to those found between constructions.

According to usage-based theories of $\mathrm{CxG}$, the meaning of constructions is derived from the action-meanings of utterances they typically appear in. My suggestion is that constructions participate in utterances as component action routines within more complex actions. And indeed, constructions may, and do, inherit specifically "actional" features of meaning from utterances. They often become associated with particular situations of 
utterance, particular kinds of speakers (Hopper 1998), particular genres and discourses

(Fairclough 1992), and particular discursive accomplishments. ${ }^{10}$

\section{Polyphony and complex enunciational structures ${ }^{11}$}

Utterances are acts participating in interaction, or dialogue, between people. But utterances also contain interactions within them. This inner dialogue or polyphony is a connecting level between the meanings of the words and constructions making up the content of the utterance and the meaning of the utterance as a whole. This section deals with some of the forms of reenactment by means of which such inner dialogue is accomplished.

Quotation is a case in point. When the speaker quotes another's words, a segment of her utterance is attributed to another person (or text, or fictional character). The audience now has to take into account the relation between two different personae when making sense of the utterance: the speaker and the person quoted. The same is true of other forms of reported speech (cf. Voloshinov 1973).

It is this relation between the personae which is being reenacted in the utterance. To illustrate the point, consider Transcript 3:

Transcript 3 (SBC031: 1005.220-1012.910)

BETH: ... He used to have ... (THROAT) .. asthma attacks, every time they'd go to Lewis[ton].

SHERRY: $[0 \mathrm{O}]=$.

... That's a drag, he must have liked her a lot.

Hunh?

.. @ $(H x)=$

Two things should be noted here. First, Lewiston is where the mother of the person under discussion lives. Secondly, Sherry's remark is ironic. Irony has been successfully analyzed in terms of polyphony (Bakhtin 1984; Sperber and Wilson 1981). Thus, the words "he must have liked her a lot" are attributed to a character (an unidentified person with naïve or stereotypical views about motherhood), while the speaker assumes a critical stance toward this character. The audience is meant to recognize and simulate the communicative action

\footnotetext{
${ }^{10}$ Constructions are established action routines, familiar to most speakers of a language. But reenactment can also be performed online, by appropriating a prior (usually immediately preceding) utterance from the ongoing conversation. Such on-the-spot reenactment has recently been studied by John W. Du Bois (forthcoming) in his theory of dialogic syntax.

${ }^{11}$ I would like to than an anonymous reviewer for several proposals for conceptualizing the issues discussed in this section.
} 
being performed by the character, but the utterance profiles not this action itself, but the act of performing it. The speaker's disagreement with the character is also meant to be recognized by the audience, in effect packing two different actions into the very same phrase.

Irony exemplifies a broader category of phenomena that Bakhtin (1984, 185-204) called "double-voiced discourse". More specifically, irony, like parody and most cases of mimicry (Couper-Kuhlen 1996) exemplifies vari-directional double-voiced discourse, where the speaker's stance toward the character is negative. In unidirectional double-voiced discourse the speaker identifies with the character, while nevertheless distinguishing herself from it. Bakhtin (1984) also discusses active double-voiced discourse, where the character is no longer merely the object of the speaker's attitude, but embodies a position that affects the speaker. Hidden polemic, where the author of an argumentative text responds to adversaries, whose identity and positions are not made explicit, is an example. A knowledgeable reader will be able to identify the implied adversary, just as one is able to identify an object by observing the motions involved in handling it. ${ }^{12}$

But let us look again at Sherry's ironical remark Transcript 3. The fact that this remark is ironic is crucial to the interpretation of her entire turn. It is possible to construct a context in which the whole utterance can be taken as non-ironic: If it were implied that because of the asthma attacks, the man will have to stop seeing his mother, Sherry's "Oh, that's a drag" would be taken to relate to this forced parting, and "He must have liked her a lot" would be heard as explaining and elaborating on this reaction. But that is not what Sherry is saying. Rather, "Oh, that's a drag" is said, non-ironically, of the asthma attacks, while the ironic remark means to suggest that the nature of the relationship between mother and son caused the attacks.

Thus the way the utterance is divided among characters, in itself, apart from any words uttered, is crucial to the correct understanding of the utterance. But there are no markers in the utterance explicitly signaling which part of it belongs to which character, which part is ironic and which is not. ${ }^{13}$ Rather, polyphony forms a separate level of

\footnotetext{
${ }^{12}$ Cf. Arie Verhagen's (2005) work on sentential negation and argumentative conjunctions. Verhagen convincingly argues for considering such constructions as involving coordination between at least two personae. Thus, in the case of sentential negation, the audience not merely perceives the construction as expressing a proposition, but actually has to entertain the negated proposition as attributed to a character and then reject it.

${ }^{13}$ People sometimes use prosodic markers to signal irony, but they are optional. Moreover, taken in themselves, prosodic markers are ambiguous. Thus, it is only in the context of an utterance interpreted as ironic, that a speaker's tone of voice can appear ironic to her audience. No objective properties of the prosody used are in
} 
reenactment, through which we place the actions identifiable within an utterance into a structure of enunciation. ${ }^{14}$ This can reach great complexity, as in Transcript 4:

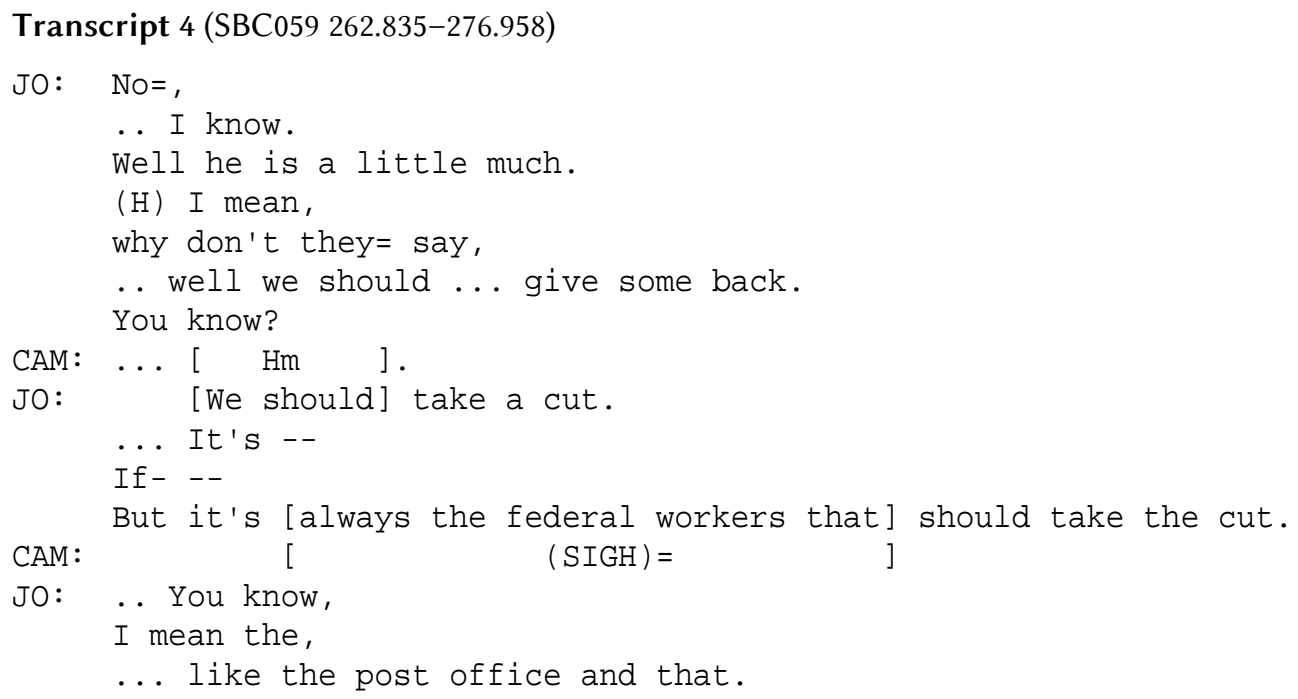

Jo is talking politics. "He" in his first turn is Newt Gingrich, the Speaker of the US House of Representatives at the time (and by implication, "they" are the Republicans or US conservatives, whose leader Gingrich was). Note, though, that Jo puts the expressions of two positions in the Republicans' mouth. The first position, expressed as: "we should give some back", "we should take a cut", he presents as acceptable (at least for the sake of the argument). ${ }^{15}$ But then he adds: "But it's always the federal workers that should take the cut".

Who do these words belong to? Jo does not think that the federal workers deserve this treatment. Rather, the second position can be seen as a response to the first (hence the "But"), made by a critic, who exposes the true intentions behind those benign statements. "We should give some back" would then be attributed to the Republicans (speaking in bad faith), while "it's always the federal workers who should take the cut" would again belong to the Republicans, but as filtered through the eyes of the critic (with whom Jo agrees), rather than directly.

These characters are not identified explicitly and are vague figures, rather than concrete individuals. Moreover, it is not clearly marked which words belong to whom, and

\footnotetext{
themselves sufficient to mark irony.

${ }^{14} \mathrm{Cf}$. the results reported in Giora (2007), which indicate that irony is processed separately and more slowly than literal and metaphoric uses of language.

${ }^{15}$ More context is needed to determine whether "why don't they say" implies this is a position Republicans could have taken but did not, or whether the statements reflect an actual (insincere) Republican argument. My analysis assumes the latter.
} 
there is room for interpretative freedom in making the assignment. Nevertheless, if we ignore the polyphonic reenactment and collapse all Jo says into one voice, the result would be an incoherent and unintelligible utterance.

\section{Segmentation of utterances}

An important player in the polyphonic reenactment that goes on in any utterance is the listener, or rather, to borrow a term from literary theory, the implied listener. In this brief section I shall argue that the reenacted part of the listener in long utterances is involved in breaking them up into shorter segments. In the following section I will note the role of the implied listener in accounting for the meaning of the utterance as a whole.

Consider Jo's utterance in Transcript 4 again. It is quite long. But at one point, roughly at the stitch between two intonation units, it is interrupted by Cam's "Hm". In Conversation Analysis this is called a continuer (Schegloff 1982) - a very brief intervention aimed to signal to the speaker that her listener is following and that she may go on. I would like to suggest that an intervention by the listener (a continuer, or another brief contribution, such as a question) always appears between phrases or intonation units ${ }^{16}$ in longer utterances, but that it is reenacted by the speaker when it is not actually uttered by her interlocutor.

For one construction, the left dislocation construction in English (in which the subject of a sentence is moved into a separate clause or sentence preceding the main sentence, as in: "John - he likes tomatoes"), this has been demonstrated in a corpus study by Ronald Geluykens (1992). Geluykens examined all appearances of left dislocation in a corpus of English conversations, as well as in samples of written texts and spoken monologue, including cases in which there was a brief turn by another speaker intervening between the announced topic and the rest of the sentence. Geluykens found that the left dislocation construction was used by speakers (and overwhelmingly also by writers) to introduce a new topic to the ongoing discourse. When there was an intervening turn between the two parts of the construction, the function of this turn was to acknowledge or accept the new topic (usually by means of a continuer). Importantly, when there was no intervening turn, there often was a short pause taking its place, but functionally the pause played the same role as the intervening turn. The pause was a slot left for the listener to acknowledge the new topic, and by continuing after it, the speaker projected an acknowledgement by the listener into her turn

\footnotetext{
${ }^{16}$ More precisely, in a conversational setting, it appears between Turn Construction Units (TCUs), as defined in Sacks, Schegloff and Jefferson (1974).
} 
(indeed, such pauses appeared in spoken monologues, and their equivalents appeared in written discourse, with the same functional implications). In the terms I am proposing here, the speaker reenacted the listener's acknowledgement.

The same reasoning applies to any break between Turn Construction Units (TCUs) as defined in Conversation Analysis (Sacks, Schegloff and Jefferson 1974). A TCU is delimited by Transition Relevance Places (TRPs), i.e. by places in which turn transition may legitimately occur. When transition does not occur, and especially in long turns, a brief pause takes its place. These pauses also occur in monologues (Du Bois 2009), and arguably clause and sentence boundaries, marked by commas and periods in writing, and by pauses when read out loud, preserve something of the same original function. And while in face-to-face conversation such breaks may reflect the fact that other speakers chose not to take the floor between two TCUs uttered by the current speaker, in extended turns and monologues the function of the pause is to reenact a sign by the listener that the speaker may keep the floor. ${ }^{17}$

\section{Utterer's meaning}

How can one formulate the pragmatic meaning of an utterance as a whole? One influential attempt to answer this question was made by Paul Grice (1957): To mean something is to intend one's audience to produce a certain response, and to do so because of realizing this intention. Grice's account of (non-natural) meaning can thus be stated in reenactment terms. It is not the actual response and motivation of the audience that defines the meaning of the utterance, but the response and motivation of the audience as intended by the speaker.

Realizing the speaker's intention also involves recognizing the reenacted audience's response.

Transcript 5 illustrates this well:

Transcript 5 (SBC058: 55.440-71.296)

SHERI : Tomorrow?

... (H) Well can you just put em in the bag,

$\ldots$ in there for now,

okay?

STEVEN: ... Ok[ay ].

SHERI: [Cause] I gotta clean up in here,

this .. place is just totally trashed,

.. cause I've done nothing this week but,

... study and be sick.

... I've got a really bad dental problem.

or something with my mouth.

STEVEN: ... Poor Mom.

\footnotetext{
${ }^{17}$ Also, as Du Bois (2009) shows, pauses between TCUs in a monologue may mark not a continuation, but a transition between parts of an utterance assigned to different characters.
} 
Earlier in the conversation Sheri's asked Steven, her 11-year-old son, to recycle some cans, and he declined. Sheri now makes an alternative request, to which he agrees, but she nevertheless goes on to explain why this is important to her. Steven's last turn reflects a keen understanding of what Sheri expects his response to be. Her previous utterance includes an appeal to pity, and feeling sorry for her is thus a projected (reenacted) audience response.

But by saying "Poor Mom" Steven implies the appeal to pity was the main aim of Sheri's utterance, which is not necessarily what she intended. In other words, the actual audience response to an utterance, not only the reenacted one, plays a significant role in how its meaning plays out. This marks the limit of reenactment as a conceptual framework: Reenactment is the projection of action in general, and of interaction and dialogue in particular into utterances, but utterances are actions, that participate in actual dialogues, and reenactment is merely a tool for the purposes people strive to attain when making them.

\section{Conclusion}

In this paper I tried to show how reenactment - the overt embodied simulation of actions and practices, including especially communicative actions and practices, within utterances makes it possible to forge an integrated EC-based account of linguistic meaning. In particular, I argued: (a) that remote entities can be referred to by reenacting actions performed with them; (b) that the use of grammatical constructions can be conceived of as the reenactment of linguistic action routines; (c) that complex enunciational structures involve a separate level of reenactment, on which characters are presented as interacting with one another within the utterance; (d) that the segmentation of long utterances into shorter units involves the reenactment of brief audience interventions between units; and (e) that the overall meaning of an utterance can be stated in reenactment terms. Further research is necessary to validate some of the assumptions made here empirically, as well as to evaluate the usefulness of the proposed conceptual framework.

My aim was to provide support to a vision of language and cognition that is entirely action-based, where action and interaction (performed or perceived) are the main currency in which human minds conduct their business. This vision also animates at least some of the approaches within EC. Following and developing it can also, so I believe, improve and deepen our understanding of language and meaning. 


\section{Acknowledgements}

I would like to thank Robert E. Sanders and Haim Marantz, as well as two anonymous reviewers, for their highly useful and thoughtful comments on earlier drafts of this paper. I would also like to thank Wendy Sandler for sharing some of her own and her colleagues' work in progress with me. Some of the ideas contained here were first presented in April 2011 at the $13^{\text {th }}$ conference of the International Association for Dialogue Analysis, “Dialogue and Representation”, Université de Montréal. While writing this paper I benefited from a postdoctoral fellowship from the Israeli Committee for Higher Education and the University of Haifa.

\section{References:}

Austin, J. L. (1962). How to do things with words. Oxford: Clarendon Press.

Aziz-Zadeh, L., \& Damasio, A. (2008). Embodied semantics for actions: Findings from functional brain imaging. fournal de Physiologie - Paris, 102 (1-3), 35-39.

Bakhtin, M. M. (1981). Discourse in the novel. In M. M. Bakhtin, The dialogic imagination: Four essays (pp. 259422). Austin: University of Texas Press.

Bakhtin, M. M. (1984). Problems of Dostoevsky’s poetics. Minneapolis: University of Minnesota Press.

Bakhtin, M. M. (1986). From notes made in 1970-71. In M. M. Bakhtin, Speech genres and other late essays (pp. 132-158). Austin, TX: University of Texas Press.

Borghi, A. M., \& Cimatti, F. (2009). Words as tools and the problem of abstract word meanings. In N. Taatgen, \& H. van Rijn (Eds.), Proceedings of the $31^{\text {st }}$ annual conference of the Cognitive Science Society (pp. 23042309). Amsterdam: Cognitive Science Society.

Borghi, A. M., \& Cimatti, F. (2010). Embodied cognition and beyond: Acting and sensing the body. Neuropsychologia, 48, 763-773.

Brandt, L., \& Brandt, P. A. (2005). Making sense of a blend: A cognitive-semiotic approach to metaphor. Annual Review of Cognitive Linguistics, 3, 216-249.

Chafe, W. L. (1993). Prosodic and functional units of language. In J. A. Edwards, \& M. D. Lampert (Eds.), Talking data: Transcription and coding in discourse research (pp. 33-43). Hillsdale, NJ: Laurence Erlbaum Associates.

Clark, A., \& Chalmers, D. (1998). The extended mind. Analysis, 58 (1), 7-19.

Cooren, F. (2010). Action and agency in dialogue. Amsterdam: Benjamins.

Coulson, S. \& Fauconnier, G. (1999). Fake guns and stone lions: Conceptual blending and privative adjectives. In B. Fox, D. Jurafsky, \& L. Michaelis (Eds.) Cognition and function in language (pp. 143-158). Palo Alto, CA: CSLI.

Croft, W. (2001). Radical construction grammar: Syntactic theory in typological perspective. Oxford: Oxford University Press.

Du Bois, J. W. (2009). Interior dialogues: The co-voicing of ritual in solitude. In G. Senft, \& E. B. Basso (Eds.) Ritual communication (pp. 317-372). Oxford: Berg Publishers.

Du Bois, J. W. (forthcoming). Towards a dialogic syntax. Cognitive Linguistics. 
Du Bois, J. W., \& Englebretson, R. (2004). Santa Barbara corpus of spoken American English, Part 3. Philadelphia: Linguistic Data Consortium.

Du Bois, J. W., \& Englebretson, R. (2005). Santa Barbara corpus of spoken American English, Part 4. Philadelphia: Linguistic Data Consortium.

Du Bois, J. W., Schuetze-Coburn, S., Cumming, S., \& Paolino, D. (1993). Outline of discourse transcription. In J. A. Edwards, \& M. D. Lampert (Eds.), Talking data: Transcription and coding in discourse research (pp. 4589). Hillsdale, NJ: Laurence Erlbaum Associates.

Ducrot, O. (1984). Le dire et le dit. Paris: Les Éditions de Minuit.

Ekić, M, \& Pascual, E. (2011). “The cigarette lighter says...”: Fictive interaction in languages without a writing system. Paper presented at the $32^{\text {nd }} \mathrm{TaBu}$ Dag linguistics conference, University of Groningen.

Fairclough, N. (1992). Intertextuality in critical discourse analysis. Linguistics and Education, 4, 269-293.

Fauconnier, G. (1994). Mental spaces: Aspects of meaning construction in natural language. Cambridge: Cambridge University Press.

Fauconnier, G., \& Turner, M. (2002). The way we think: Conceptual blending and the mind's hidden complexities. New York: Basic Books.

Fillmore, C. J., Kay, P., \& O’Connor, M. C. (1988). Regularity and idiomaticity in grammatical constructions: The case of let alone. Language, 64 (3), 501-538.

Fischer, M., \& Zwaan, R. (2008). Embodied language: A review of the role of the motor system in language comprehension. The Quarterly fournal of Experimental Psychology, 61, 825-850.

Gallese, V. (2003). The manifold nature of interpersonal relations: The quest for a common mechanism. Philosophical Transactions of the Royal Society of London, B, 358, 517-528.

Gallese, V. (2008). Mirror neurons and the social nature of language: The neural exploitation hypothesis. Social Neuroscience, 3, 317-333.

Gallese, V., \& Lakoff, G. (2005). The brain’s concepts: The role of the sensory-motor system in conceptual knowledge. Cognitive Neuropsychology, 22, 455-479.

Gasparov, B. M. (2010). Speech, memory, and meaning: Intertextuality in everyday language. Berlin: De Gruyter.

Geluykens, R. (1992). From discourse process to grammatical construction: On left-dislocation in English, Amsterdam: John Benjamins.

Giora, R. (2007). “And Olmert is a responsible man”: On the priority of salience-based yet incompatible interpretations in nonliteral language. Cognitive Studies, 14 (3), 269-281.

Goldberg, A. E. (2006). Constructions at work: The nature of generalization in language. Oxford: Oxford University Press.

Goldman, A., \& de Vignemont, F. (2009). Is social cognition embodied? Trends in Cognitive Sciences, 13 (4), 154159.

Grafton, S. T. (2009). Embodied cognition and the simulation of action to understand others. Annals of the New York Academy of Sciences, 1156, 97-117.

Grafton, S. T., Arbib, M. A., Fadiga, L., \& Rizzolatti, G. (1996). Localization of grasp representations in humans by positron emission tomography. 2. Observation compared with imagination. Experimental Brain Research, 112 (1), 103-111.

Grice, H. P. (1957). Meaning. The Philosophical Review, 66 (3), 377-388. 
Hopper, P. J. (1998). Emergent grammar. In M. Tomasello (Ed.), The new psychology of language: Cognitive and functional approaches to language structure (pp. 155-202). Mahwah, NJ: Lawrence Earlbaum Associates.

Iacoboni, M., Woods, R. P., Brass, M., Bekkering, H., Mazziotta, J. C., \& Rizzolatti, G. (1999). Cortical mechanisms of human imitation. Science, 286, 2526-2528.

Jirak, D., Menz, M. M., Buccino, G., Borghi, A. M., \& Binkofski, F. (2010). Grasping language - A short story on embodiment. Consciousness and Cognition, 19, 711-720.

Lakoff, G., \& Johnson M. (1980). Metaphors we live by. Chicago: University of Chicago Press.

Langacker, R. W. (1987). Foundations of cognitive grammar. Stanford: Stanford University Press.

Merleau-Ponty, M. (1962). Phenomenology of perception. New York: Routledge \& Kegan Paul.

Noë, A. (2004). Action in perception. Cambridge, MA: MIT Press.

Padden, C., Aronoff, M., Meir, I., \& Sandler, W. (2010). In search of grammar. Paper presented at the Theoretical issues in sign language research conference, Purdue University.

Pascual, E. (2002). Imaginary trialogues: Conceptual blending and fictive interaction in criminal courts. Utrecht: LOT.

Pulvermüller, F. (2005). Brain mechanisms linking language and action. Nature Reviews Neuroscience, 6 (7), 576582.

Rizzolatti, G., \& Craighero, L. (2004). The mirror-neuron system. Annual Review of Neuroscience, 27, 169-192.

Rizzolatti, G., Fadiga, L., Gallese, V., \& Fogassi, L. (1996). Premotor cortex and the recognition of motor actions. Cognitive Brain Research, 3, 131-141.

Rommetveit, R. (1992). Outlines of a dialogically based social-cognitive approach to human cognition and communication. In A. H. Wold (Ed.), The dialogical alternative: Towards a theory of language and mind (pp. 19-44). Oslo: Scandinavian University Press.

Rosch, E. (1973). Natural categories. Cognitive Psychology, 4, 328-350.

Sacks, H., Schegloff, E. A., \& Jefferson, G. (1974). A simplest systematics for the organization of turn-taking for conversation. Language, 50 (4), 696-735.

Schegloff, E. A. (1982). Discourse as an interactional achievement: Some uses of 'uh huh' and other things that come between sentences. In. D. Tannen (Ed.), Analyzing discourse: Text and talk (pp. 71-93). Washington, DC: Georgetown University Press.

Sperber, D., \& Wilson, D. (1981). Irony and the use - mention distinction. In P. Cole (Ed.), Radical Pragmatics (pp. 295-318). New York: Academic Press.

Tylén, K., Weed, E., Wallentin, M., Roepstorff, A., \& Frith, C. (2010). Language as a tool for interacting minds. Mind and Language, 25 (1), 3-29.

Umiltà, M. A., Kohler, E., Gallese, V., Fogassi, L., Fadiga, L., Keysers, C., \& Rizzolatti, G. (2001). "I know what you are doing": A neurophysiological study. Neuron, 31 (1), 155-165.

Verhagen, A. (2005). Constructions of intersubjectivity. Discourse, syntax, and cognition. Oxford: Oxford University Press.

Voloshinov, V. N. (1973). Marxism and the philosophy of language. New York: Seminar Press.

Vries, L. de. (2010). Direct speech, fictive interaction, and bible translation. The Bible Translator, 61(1), 31-40.

Wilson, M. (2002). Six views of embodied cognition. Psychonomic Bulletin \& Review, 9 (4), 625-636.

Wittgenstein, L. (1953). Philosophical investigations. Oxford: Blackwell. 
Zlatev, J., Racine, T., Sinha, C., \& Itkonen, E. (eds.) (2008). The shared mind: Perspectives on intersubjectivity. Amsterdam: Benjamins. 